\title{
Interview: Discussing Value Proposition Research in the Context of New Companies Committed to Scaling Early and Rapidly Adrian Payne, Pennie Frow, Stoyan Tanev
}

\author{
" Considering that value propositions in one level of a business ecosystem can impact all other \\ levels offers a powerful approach to examining the value proposition process. ")
}

Adrian Payne \& Pennie Frow

\section{Introduction by Stoyan Tanev}

Value proposition (VP) development has become the subject of growing research interest in the last 20 years. The number of research studies has grown especially in the last 5 years, including several recent review papers summarizing key developments and identifying directions of future research (Goldring, 2017; Eggert et al., 2018; Bailetti et al., 2020; Payne et al., 2020). In addition, the VP concept has successfully joined the vocabulary of business practitioners and entrepreneurs. This should not come as a surprise because the term was introduced in 1983 by Michael Lanning in a practitioner context, within an internally circulated McKinsey Staff Paper (Lanning \& Michaels, 1988).

Interestingly, the VP concept can be associated with a peculiar paradox. According to Webster (2002), a "value proposition" is a company's single most important organizing principle. At the same time, the concept has been often used casually and applied in a trivial fashion, rather than in a more strategic, rigorous, and actionable manner. Thus, "businesses often formulate them [VPs] as promises to customers, hoping to influence attitudes and behavior, but then fail to take those promises seriously" (Lanning, 2020). According to Eggert et al. (2020), "despite its frequent mention in the business and academic press, the value proposition concept remains poorly understood and executed".

The objective of the present special issue is to contribute to unfolding some of the challenges of VP development by new companies committed to scaling early and rapidly. Why focus on such companies? The answer is twofold. First, most new firms are facing a scale-up challenge. This challenge is not unique to a specific country or geographical region, but is especially relevant in Canada where, for example, a recent report by the Toronto Board of Trade pointed out that, "Canada is a terrific start-up nation but a dismal failure as a scaleup nation" (Crane, 2019). Second, most of the extant research examines the context of established companies, rather than new companies committed to scaling. The usual focus is thus on communicating the ways to reconfigure resources owned by external partners and other preferred stakeholders for the sake of maximizing value captured by a focal company and its customers.

However, the reality faced by new companies committed to scaling is quite different. In addition to the challenges that such companies face in engaging with external resource owners to access, combine, deploy, and align internal and external resources, they need to operate across borders, innovate relentlessly, and be ready to adopt emerging artificial intelligence (AI), and other digital technologies as part of their scaling mechanisms, as well as negotiate with investors to enable the execution of capital investment programs that could help them meet their scaling objectives (Bailetti et al., 2020). Thus, new companies that wish to scale early and rapidly need to acquire VP development capabilities that go beyond those required by companies with moderate growth objectives. They need to adopt an explicit multiple stakeholder perspective on VP development, as well as explore how AI resources and digital capabilities can help them enhance the scaling potential of their VPs. In this sense, the context of such companies offers an opportunity for both further advancing VP research and 


\title{
Interview: Discussing Value Proposition Research in the Context of New Companies Committed to Scaling Early and Rapidly
}

\author{
Adrian Payne, Pennie Frow, Stoyan Tanev
}

shaping practical actionable insights for executive managers of new companies committed to scaling early and rapidly.

The focus of the special issue opens some contemporary questions about the extent to which existing research has already addressed some of the issues associated with new scaling companies. This is the reason behind the idea of interviewing two scholars who have significantly contributed to the advancement of VP research in the last 20 years, Dr. Adrian Payne, Professor of Marketing at the University of New South Wales, and Dr. Pennie Frow, Professor of Marketing Management and Strategy in the University of Sydney Business School, Australia. A search in the Web of Science academic database shows that since 2008 they have co-authored more than a dozen articles in highly respected academic journals. Such publication activity shows a systematic engagement with VP research focusing on many important issues such as: value co-creation through resource sharing and integration (Payne et al., 2008; Storbacka et al., 2012; Frow et al., 2016), multiple stakeholder and service ecosystem perspectives on VP development (Frow \& Payne, 2011; Ballantyne et al., 2011; Frow et al., 2014; Frow et al., 2016), enhancing the development of a VP through the deconstruction of VPs of exemplar companies (Payne \& Frow 2014), specifics of the VP concept and its implementation in a business-to-business (B2B) context (Eggert et al., 2018; Payne et al., 2020), the emergence, development, and application of the VP concept in marketing (Payne et al., 2017), and the role of VPs as market-shaping devices (Nenonen et al., 2020).

\section{Interview with Adrian Payne and Pennie Frow}

Tanev: The format of our interview will be a bit unusual since it is with two different interviewees at the same time. So, we will just ask the questions and let Professors Payne and Frow choose how to reply.

Question: How did your cooperation start and to what extent did VP research play a role in your scientific cooperation?

Payne and Frow: Our cooperation commenced in the 1990s in the UK when Adrian was Professor of Marketing at Cranfield University and Pennie was a Visiting Fellow at Cranfield University and a Senior
Consultant in the Cranfield Marketing Planning Centre. We shared a common view that much research in marketing has little practical application, and that more scholarly research should focus on being practical, relevant, and applied. Our joint research initially looked at a range of strategic marketing issues including developing a segmented service strategy, integrating employee, customer, and shareholder value through an enterprise performance model, relationship value management, multichannel integration, co-creation and most recently, market shaping. Adrian started thinking more deeply about the VP concept when a McKinsey colleague shared Michael Lanning's unpublished article from the McKinsey Staff Papers series. We agreed this was a really important topic for investigation and incorporated a consideration of value propositions into several our subsequent books and journal articles. About 10 years ago we started publishing a series of articles on VPs in a range of journals, including Industrial Marketing Management, European Marketing Journal, and the Journal of Services Management. Further work followed in the Journal of the Academy of Marketing Science, with subsequent articles appearing in Industrial Marketing Management. We collaborated with various scholars, including Andreas Eggert, Lena Steinhoff, Kaj Storbacka, Suvi Nenonen, David Ballantyne, and Richard Vary. These thought leaders have had a major influence on our joint work.

Tanev: You recently co-edited a special issue in the Industrial Marketing Management Journal (together with A. Eggert and L. Steinhoff) that focused on "Understanding and managing customer value propositions". In the Editorial, you pointed out that the customer VP emerged from within the field of marketing and was not borrowed from other disciplines. You wrote: "While adjacent academic disciplines such as human resource management have adopted the value proposition concept and conceptualized e.g. the employer value propositions, the customer value proposition remains at the heart of the marketing discipline. Indeed, no other academic discipline investigates the customer value proposition as one of its key constructs" (Eggert et al., 2020). One can feel an understandable marketing disciplinary "pride" in this statement.

Question: Can we see the ongoing adoption of the concept by other business disciplines - human resource management, supply chain management, investor 


\section{Interview: Discussing Value Proposition Research in the Context of New Companies Committed to Scaling Early and Rapidly}

\section{Adrian Payne, Pennie Frow, Stoyan Tanev} relations, business model innovation - as a sign of its
practical potential and value?

Payne and Frow: Shelby Hunt, in a recent article in AMS Review (Hunt, 2020), noted that the intellectual health of marketing needs indigenous theory development. However, he argued that the discipline of marketing, almost exclusively, uses concepts and theories from other disciplines and applies them to research and marketing practices. The concept of a "customer value proposition" is indigenous to marketing. The term "value proposition" was originally conceived as a proposition for customers, thus, in our view, it clearly comes from marketing.

Since then, as you point out, the concept has been adopted in several other disciplinary areas. The concept has mainly been applied in human resource management through the concept of an "employee value proposition", and in the field of strategy as a component of the business model. We are also starting to see some emerging literature on shareholder value propositions. However, the VP concept clearly has application to all key stakeholders of a business, as we pointed out in our article in the European Journal of Marketing a decade ago (Frow \& Payne, 2011). We believe that the existing and emerging work on VPs highlights the practical potential and value of the concept across different stakeholder groups. As marketing borrows heavily from other disciplines, we believe it is perfectly appropriate for other disciplines to also borrow from marketing. Cross-functional thinking needs to be embedded more deeply in both business and academia generally.

Tanev: Almost every serious publication on VPs points out that the concept remains poorly understood and executed. Some scholars see it as just one of the building blocks in business model frameworks. Others see it as belonging to the realm of a company's overall business strategy, which requires effectuating a specific busines model (Onetti et al., 2012).

Question: How can you explain the paradox of the coexistence of both a great interest in and poor understating of the same concept? Can we find one of the sources of misunderstanding exactly in the multiplicity of its applicability contexts?

Payne and Frow: Michael Lanning, one of the originators of the concept, whilst working at McKinsey and through his subsequent consulting experience to the present time, has confirmed just how poorly understood and executed the concept is. Our work and that of many others concur with this finding. It seems it is just too easy for managers to throw the concept around in a casual manner, almost like a buzzword, and not consider it seriously enough.

The fact is that every enterprise has a VP for customers, otherwise they would not be in business. However, it appears that company VPs are much more likely to be implicit rather than explicit. If they are explicit, such VPs can often be compared with motherhood statements typically made in connection with mission statements. Existing enterprise-level VPs that are made explicit frequently do not meet the tests suggested in the literature for strong and resonant VPs.

However, this is not to suggest that only companies with formally articulated and written VPs may become highly successful. Some companies can be extremely successful with merely implicit or informal VPs. Our 2014 article in the European Journal of Marketing (Payne \& Frow, 2014) discussed the case of Shouldice Hospital, an organization described by some as one of the best service companies in the world. At the time of writing, they had not produced a formal written VP, yet their VP to customers was recognized and clearly understood, largely through word-of-mouth and cultural understanding.

Lack of recognition about the real importance and value of VPs, together with the complexity and effort required to develop a VP, at least partially explains this paradox. Whilst the processes of value design assessment, value quantification, value communication, value documentation, and value verification can themselves be quite complex (Payne et al., 2020), they are easier to address in business markets than consumer markets where value quantification is more subjective.

Tanev: The topic of the present special issue focuses on new companies committed to scaling early and rapidly. The context requires a multiple stakeholder perspective on VP development that brings in questions about the alignment between various VPs, as well as alignment between the portfolio of VPs and a company's scaling objectives. 


\section{Interview: Discussing Value Proposition Research in the Context of New Companies Committed to Scaling Early and Rapidly}

\section{Adrian Payne, Pennie Frow, Stoyan Tanev}

Question: Do you find this context distinctive enough to the extent that it would require a different approach to VP development?

Payne and Frow: The context of new companies committed to scaling at an early stage and continuing to do this at a rapid rate is clearly a special case and also an area of considerable current research interest. To date, relatively little work has been done in this area, hence the importance of this Special Issue.

New companies at an early stage of development are frequently in a state of flux and rapid growth. Such companies experiencing substantive growth may be product-focused and can be internally-oriented. Effectual and co-creative approaches would seem appropriate in this context (Payne et al., 2008, Reuber et al. 2016).

Hopefully, VPs account for the complexities of scaling up quickly. In particular, IT systems need to be "industrialized", so they do not fall over as scale is increased, just as supply and demand need continual balancing.

Tanev: You are among the first to emphasize the need for adopting a multiple stakeholder perspective on VP development (Ballantyne et al., 2011; Frow \& Payne, 2011). You have also suggested a specific service ecosystem perspective (Frow et al., 2014; Frow et al., 2016), pointing out opportunities for going beyond traditional enterprise-stakeholder views. Other scholars have also used the "ecosystem" construct to discuss how to shape VPs. According to Adner (2017), ecosystems should provide "the alignment structure of the multilateral set of partners that need to interact in order for a focal value proposition to materialize".

Question: What is the best way to describe the interacting multiplicity of actors involved in the value creation process? If the "ecosystem" construct is the most suitable way of doing that, which "ecosystem" concept could be most appropriate? To what extent does the choice of a specific ecosystem concept affect the process of VP development?

Payne and Frow: We believe that the ecosystem perspective is simply one focal perspective that can be adopted. We think the perspective being adopted hinges around the perspective of the specific stakeholder being considered.

Ecosystems are very complex, and as recent marketing literature suggests, the topic is still embryonic in terms of its development with respect to understanding the applications to / implications for marketing systems. However, considering that VPs in one level of a business ecosystem can impact all other levels offers a powerful approach to examining the VP process. This perspective also highlights how developing a VP that addresses one actor can have implications for all other actors in the ecosystem.

Question: Given the multiplicity of actors and VPs in an ecosystem perspective, how do you conceptualize the alignment between actors, VPs, and the overall business objective of a company?

Payne and Frow: We use an ecosystem perspective of VPs to explain how and why VPs adapt and change, as each actor proposes and receives VPs within a company. Using an ecosystem perspective suggests how the tensions that arise between actors and the business objectives of a company can be successfully managed. Each actor in an ecosystem offers a reciprocal VP, whereby the company and actor mutually adapt to each others' goals. Unless ecosystem actors and the company are mutually satisfied by what is offered and what is received, the relationship will be fractured. As each actor may have quite different goals and perspectives of a VP, using an ecosystem approach suggests how tensions can be better managed. What is good for a business must also be good for other stakeholders, otherwise its VP cannot be sustained. We thus see VPs in a business ecosystem as constantly emerging, adapting, and responding in the context of various actors involved.

Question: How would you define the key priorities for future VP research?

Payne and Frow: Despite recent interest in VP research, this is still a nascent area. There are thus many aspects involving VPs that require further investigation. In a recent article we outlined 37 specific questions to investigate under nine broad headings (Payne et al., 2017). We would highlight several key priorities: the type and extent of VP adoption across industries and at various stages of enterprise development, VPs and their impact on customer perceptions, how brand reputation and customer relationships impact the success of VPs, 


\section{Interview: Discussing Value Proposition Research in the Context of New Companies Committed to Scaling Early and Rapidly}

\section{Adrian Payne, Pennie Frow, Stoyan Tanev}

how VPs stimulate innovation and co-creation between organizations and their customers, best in class practices for identifying functional/crossfunctional mechanisms will that encourage the develop of superior VPs, and the impact of VPs on the effectiveness of marketing strategy implementation. This shows that much work of real managerial value remains to be done!

Question: Based on your current research wisdom, what would be your key message to practitioners with respect to their VP development practices?

Payne and Frow: Our key message for practitioners would be: (a) put effort into understanding the complex managerial task of identifying designing, developing, and operationalizing VPs, (b) assess the appropriate level of VP granularity, that is, can the VP be focused at a company level, should a more nuanced and targeted focus on specific segments be adopted, or is it appropriate to develop VPs at the individual customer level (for example, for major B2B customers)?, and (c) determine where responsibility lies within the company for VP development and implementation in order to allocate appropriate resources and ensure monitoring by top management. Our recent article (Payne et al., 2020) adopts clear and practical guidelines for managers regarding an organization's VP development practices.

Summary by Tanev: Expressing my deep gratitude to professors Adrian Payne and Pennie Frow for their cooperation, I can highlight some of the key points of this interview as follows.

- The term VP was originally conceived as a proposition for customers and it is clearly indigenous to marketing. However, existing and emerging VPs research highlights the practical potential and value of the concept across different stakeholder groups.

- Managers should restrict throwing the VP concept around in a casual manner, and not considering it seriously enough.

- VPs can be shaped in both implicit and explicit ways. Many existing explicit company VPs do not meet the established research criteria for strong and resonant VPs. At the same time, some companies can be extremely successful with implicit or informal VPs.
- The context of new companies committed to scaling early and rapidly is clearly a special case and an area of considerable research interest which deserves serious attention.

- The ecosystem perspective is simply one focal perspective that can be adopted in addressing the VP practices of new scaling firms.

- Considering how VPs in one level of the ecosystem impact all other levels offers a powerful approach to examining the VP process.

- An ecosystem perspective helps in conceptualizing how tensions between the key stakeholders and the business scaling objectives of a company can be successfully managed.

- Practitioners should:

- put efforts into understanding the complex managerial tasks of identifying designing, developing, and operationalizing VPs

- assess the appropriate level of VP granularity - the firm level, specific stakeholder segment or individual customer level

- determine where responsibility lies within the firm for VP development and implementation

- allocate appropriate resources and ensure monitoring by top management.

- Scholars interested in VP research could consult the recent article by Payne et al. (2017) outlining 37 open research questions organized under nine broad headings. 


\title{
Interview: Discussing Value Proposition Research in the Context of New Companies Committed to Scaling Early and Rapidly
}

\author{
Adrian Payne, Pennie Frow, Stoyan Tanev
}

\section{References}

Bailetti, T., Tanev, S., \& Keen, C. 2020. What Makes Value Propositions Distinct and Valuable to New Companies Committed to Scale Rapidly? Technology Innovation Management Review, 10(6): 14-27. DOI: http://doi.org/10.22215/timreview/1365

Ballantyne, D., Frow, P., Varey, J.R., \& Payne, A. 2011. Value Propositions as Communication Practice: Taking a wider view. Industrial Marketing Management, 40(2): 202-210.

DOI: $10.1016 /$ j.indmarman.2010.06.032

Crane, D. 2019. It's Time for Canada to Focus on the Scale-Up Challenge. IT World Canada. https://www.itworldcanada.com/article/its-time-forcanada-to-focus-on-the-scale-up-challenge/420027

Eggert, A., Frow, P., Payne, A., \& Steinhoff, L. 2020. Understanding and Managing Customer Value Propositions: Introduction to the special issue. Industrial Marketing Management, 87: 242-243. DOI: 10.1016/j.indmarman.2020.01.007.

Eggert, A., Ulaga, W., Frow, P., \& Payne, A. 2018. Conceptualizing and Communicating Value in Business Markets: From value in exchange to value in use. Industrial Marketing Management, 69: 80-90. DOI: 10.1016/j.indmarman.2018.01.018.

Frow, P., McColl-Kennedy, J.R., Payne, A. 2016. Cocreation Practices: Their role in shaping a health care ecosystem. Industrial Marketing Management, 56, July: 24-39.

DOI: 10.1016/j.indmarman.2016.03.007

Frow, P., McColl-Kennedy, J.R., Hilton, T., Davidson, A., Payne, A., Brozovic, D. 2014. Value Propositions: A service ecosystems perspective. Marketing Theory, 14(3): 327-351.

DOI: $10.1177 / 1470593114534346$

Frow, P., \& Payne, A. 2011. A Stakeholder Perspective of the Value Proposition Concept. European Journal of Marketing, 45(1-2): 223-240.

DOI: $10.1108 / 03090561111095676$

Goldring, D. 2017. Constructing Brand VP Statements: a systematic literature review. Journal of Marketing Analytics, 5(2): 57-67.

DOI: $10.1057 / \mathrm{s} 41270-017-0014-6$

Hunt, S.D. 2020. Indigenous Theory Development in Marketing: The foundational premises approach. AMS Review, 10(1): 8-17.

DOI: $10.1007 / \mathrm{s} 13162-020-00165-\mathrm{w}$

Lanning, M. 2020. Try Taking Your Value Proposition Seriously - Why delivering winning value propositions should be but usually is not the core strategy for B2B (and other businesses). Industrial Marketing Management, 87: 306-308.

DOI:

https://doi.org/10.1016/j.indmarman.2019.10.011.

Nenonen, S., Storbacka, K., Sklyar, A., Frow, P., \& Payne, A. 2020. Value Propositions as Market-Shaping Devices: A qualitative comparative analysis. Industrial Marketing Management, 87: 276-290.

DOI: 10.1016/j.indmarman.2019.10.006.

Onetti, A., Zucchella, A., Jones, M., \& McDougall-Covin, P. 2012. Internationalization, Innovation and Entrepreneurship: business models for new technology-based firms. Journal of Management \& Governance, 16: 337-368.

DOI: https://doi.org/10.1007/s10997-010-9154-1

Payne, A., Frow, P., Steinhoff, L., \& Eggert, A. 2020. Toward a Comprehensive Framework of Value Proposition Development: From strategy to implementation. Industrial Marketing Management, 87: 244-255

DOI: 10.1016/j.indmarman.2020.02.015

Payne, A., Frow, P., Eggert, A. 2017. The Customer Value Proposition: evolution, development, and application in marketing. Journal of the Academy of Marketing Science, 45(4): 467-489.

DOI: $10.1007 / \mathrm{s} 11747-017-0523-\mathrm{Z}$

Payne, A., \& Frow, P. 2014. Deconstructing The Value Proposition of an Innovation Exemplar. European Journal of Marketing, 48(1-2): 237-270.

DOI: 10.1108/EJM-09-2011-0504

Payne, A., \& Frow, P. 2014. Developing Superior Value Propositions: a strategic marketing imperative. Journal of Service Management, 25(2): 213-227.

DOI: 10.1108/JOSM-01-2014-0036

Payne, A., Storbacka, K., \& Frow, P. 2008. Managing the Co-creation of Value. Journal of the Academy of Marketing Science, 36(1): 83-96.

DOI: $10.1007 / \mathrm{s} 11747-007-0070-0$

Reuber, A. Rebecca, Fischer, E., \& Coviello, N. 2016. Deepening the Dialogue: New directions for the evolution of effectuation theory. Academy of Management Review, 41(3): 536-540.

DOI: https://doi.org/10.5465/amr.2015.0217

Storbacka, K., Frow, P., Nenonen, S., Payne, A. 2012. Designing Business Models for Value Co-creation. Special Issue - Toward a Better Understanding of the Role of Value in Markets and Marketing. Review of Marketing Research, 9:51-78.

DOI: 10.1108/S1548-6435(2012)0000009007

Webster, F.E. 2002. Market-driven management: How to define, develop and deliver customer value (2nd ed.). Hoboken, NJ: John Wiley \& Sons. 


\section{Interview: Discussing Value Proposition Research in the Context of New Companies Committed to Scaling Early and Rapidly}

\section{Adrian Payne, Pennie Frow, Stoyan Tanev}

on several closely related research areas within this field, including: co-creation, services marketing, relationship marketing, internal marketing, customer relationship management, customer value, and value proposition development. She has a special interest in researching the services sector and especially healthcare. Pennie Frow is currently the Lead Chief Investigator of a health care research project funded by the Australian Research Council, investigating co-creation practices in a new hospital context. Another major project involves investigating the impact of customer value propositions, exploring both firm and customer outcomes. Prof. Frow has published in academic and practitioner journals including the Journal of Marketing, Journal of the Academy of Marketing Science, European Journal of Marketing, Journal of Business Research, Industrial Marketing Management, and the Journal of Marketing Management.

Citation: Payne, A., Frow, P., Tanev, S. 2021. Interview: Discussing Value Proposition Research in the Context of New Companies Committed to Scaling Early and Rapidly. Technology Innovation Management Review, 11(4): 6-12.

http://doi.org/10.22215/timreview/1432

Keywords: Value proposition, business ecosystems, new scaling companies, implicitly vs. explicitly formulated value propositions, value proposition alignment 